\title{
Cultivares de Caqui Japonés en Florida ${ }^{1}$
}

\section{Ali Sarkhosh, Peter C. Andersen, y Dustin Huff; traducción por Jonathan Clavijo Herrera²}

\section{Historia}

El caqui japonés, Diospyros kaki L., es originario de China y fue cultivado por primera vez en Florida en el año 1870. El algún momento hubo plantaciones comerciales de cultivares astringentes con alrededor de 22.750 árboles. Debido a las dificultades de comercialización, esta industria cesó. California es el mayor productor de caquis japoneses, seguido de Florida y el sur de Texas. Según los datos del Censo de Agricultura de 2017 para toda la población de caquis en los Estados Unidos, la mayoría de las plantaciones son a pequeña escala. De las cerca de 2,400 fincas que cultivan la fruta, alrededor del $70 \%$ tienen menos de 1 acre, y 90\% tienen menos de 5 acres. En 2017, la superficie cultivada en Florida era de alrededor de 266 acres, en lugar de los 324 acres en 2012, y debajo del máximo estimado de 500 acres a mediados de la década de 1990. Sin embargo, el número de fincas productoras de caqui en Florida ha aumentado de 164 a 227 durante el período 2012-2017, haciendo mayor hincapié en la naturaleza de pequeña escala de la superficie promedio de fincas en esta industria. Los árboles crecen y fructifican mejor en el centro y norte de Florida, y pueden producir altos rendimientos de fruta de buena calidad. En el sur de Florida, la calidad de los frutos de tipo astringentes es mejor que la de los de tipo no astringentes.
Los caquis japoneses fueron introducidos a los Estados Unidos por el comandante M. C. Perry en 1856. El Departamento de Agricultura de los Estados Unidos importó muchos árboles en la década de 1870 y los plantó en el sur del país. Los inmigrantes de China y Japón también introdujeron diferentes cultivares a California antes de 1919. El profesor Harold Hume de la Universidad de Florida fue uno de los primeros en estudiar el caqui japonés en Estados Unidos, y en 1914 desarrolló un sistema de clasificación que es la base de los sistemas utilizados hoy en día. Hume, junto con George Tabor del vivero Glen St. Mary, también trabajó con mejoramiento y evaluaciones de cultivares. Durante los años 60 y 70, el juez Ware y el Dr. Robert Dunstan importaron y evaluaron muchas cultivares japoneses importantes. En la Universidad de Florida, el profesor Ralph Sharpe probó, evaluó y publicó información sobre caquis. Durante la década de 1980, se introdujeron nuevos cultivares especialmente no astringentes, que fueron estudiados en el departamento de Ciencias Hortícolas de la UF/IFAS. Florida tiene una rica historia sobre caquis japoneses y ha sido un estado prominente en evaluaciones de cultivares, con sitios en Gainesville, Chiefland y Monticello, evaluados durante las décadas de 1980 y 1990. Botryosphaeria spp. y el hongo del género Cercospora son las principales limitaciones para la producción de caqui en Florida.

1. Este documento es SP101-Spa, uno de una serie del Departamento de Ciencias Hortícolas, Servicio de Extensión UF/IFAS. La narrativa en este documento proviene principalmente de "Caquis Orientales en Florida", publicado por primera vez por Miller y Crocker (1994), disponible públicamente en la Biblioteca Digital de UF: https://ufdc.ufl.edu/IR00005924/00001, actualizado con nuevas cifras e información sobre cultivares en noviembre de 2019. Visite el sitio web de EDIS en: https://edis.ifas.ufl.edu.

2. Ali Sarkhosh, profesor asistente y especialista en extensión, Departamento de Ciencias Hortícolas; Peter C. Andersen, profesor emérito, Departamento de Ciencias Hortícolas, Centro de Investigación y Educación del Norte de Florida en Quincy; Dustin Huff, Científico Biológo, Departamento de Ciencias Hortícolas; y Jonathan Clavijo-Herrera, estudiante de doctorado, Departamento de Ciencias Hortícolas; Servicio de Extensión UF/IFAS, Gainesville, FL 32611.

The Institute of Food and Agricultural Sciences (IFAS) is an Equal Opportunity Institution authorized to provide research, educational information and other services

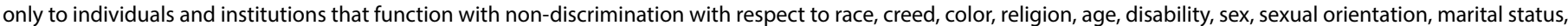

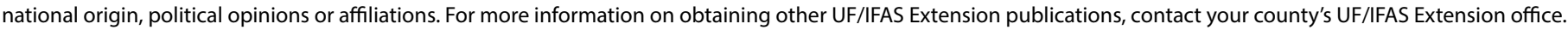
U.S. Department of Agriculture, UF/IFAS Extension Service, University of Florida, IFAS, Florida A \& M University Cooperative Extension Program, and Boards of County Commissioners Cooperating. Nick T. Place, dean for UF/IFAS Extension. 
Muchos cultivares de caqui en Florida existen como resultado tanto de importaciones, como de árboles propagados desde plántulas. Los nombres de los cultivares de caqui a menudo representan una aproximación a los diversos nombres en lengua asiática por los que se conocía a los árboles importados originalmente. Actualmente, tenemos una serie de cultivares con nombres y significados en lengua asiática o pseudo asiática, así como nombres derivados del inglés estadounidense. Algunos nombres derivados de lenguas asiáticas tienen los siguientes significados: 'Kaki' o 'Gaki'-caqui; 'Wase'-early, temprano; 'Hana'- flower of, flor de; 'Tanenashi' - without seeds, sin semillas; 'Fuyu' - winter, invierno; 'Saijo'-best, el mejor; 'Gosho'-imperial palace, palacio imperial; 'Ichi'-number one, número uno; y 'Ki'-life, vida.

Los caquis japoneses no están incluidos en la lista de malezas nocivas en Florida del Departamento de Agricultura de los Estados Unidos (USDA), ni en la lista de Especies de Plantas Invasivas del Consejo de Malezas Exóticas de Florida (Florida Exotic Pest Plant Council).

\section{Caracteristícas del Caqui}

\section{Clasificación}

El caqui se clasifica de dos maneras, con base en las características de la fruta. La primera clasificación establece dos categorías de frutos; astringentes y no astringentes. La primera categoría, los cultivares astringentes, se refiere a frutos cuyo sabor provoca el fruncimiento de la boca, adormece la lengua y constriñe la garganta. Este sabor es causado por substancias astringentes, como los taninos. El sabor astringente es dominante en plátanos no maduros, caquis no maduros y bellotas, y evita que sean devorados (Figura 1). El compuesto que causa la sensación astringente al comer caquis es un tanino soluble en agua (tanino caqui), que se encuentra en las células contenedoras de taninos de la fruta. Cuando estas células estallan durante el proceso de masticación, el tanino es adsorbido por las proteínas en la lengua, lo que genera una sensación de deshidratación. Las frutas astringentes deben ser suaves o tratadas artificialmente para eliminar la astringencia y hacerlas adecuadas para el consumo. Los frutos de la categoría no astringentes pierden la característica de astringencia mientras todavía son duros y se pueden comer duros o suaves.

La segunda clasificación se refiere al color de la pulpa de la fruta cuando las semillas están presentes. En los caquis de polinización variante, la pulpa es oscura y rayada alrededor de las semillas, pero de color naranja claro cuando no tiene semillas. Los caquis de polinización constante carecen de rayas oscuras en la pulpa independientemente de las semillas. En los cultivares astringentes de polinización variante, la pulpa oscura no es astringente incluso cuando está dura; por lo tanto, los cultivares astringentes que contienen semillas y son de polinización variante se comportan como frutos no astringentes. La cantidad de coloración oscura de la pulpa alrededor de las semillas varía de acuerdo con el cultivar. En la mayoría de las áreas del mundo, los frutos de tipo astringente y polinización variante, que tienen una gran cantidad de pulpa oscura, se clasifican como cultivares no astringentes. Sin embargo, típicamente en Florida, estos caquis se cultivan sin polinizadores, y su fruta astringente sin semillas requiere clasificarlos como frutos de tipo astringentes. Algunas manchas oscuras se pueden encontrar en la pulpa de 'Fuyu' y otros cultivares no astringentes. Esto no está vinculado a la producción de semillas y no tiene importancia para el sistema de clasificación variante-constante.
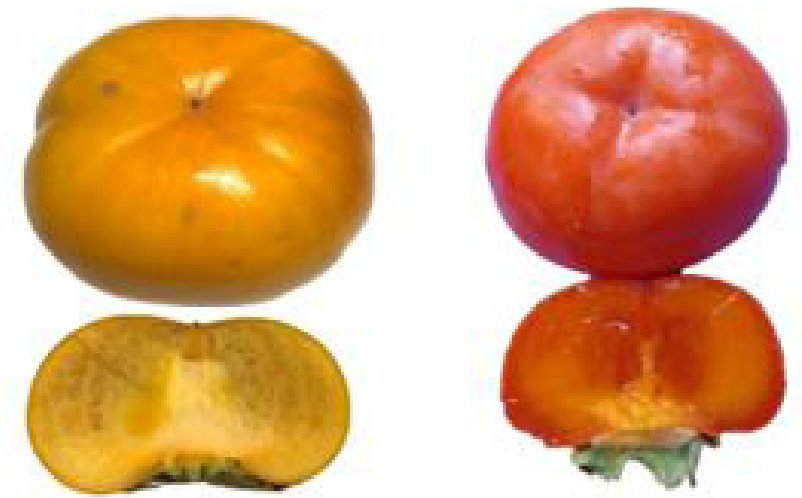

Figura 1. Caqui 'Fuyu' (izquierda) no astringente y caqui 'Hiratanenashi' astringente (derecha), cultivares listos para el consumo. Créditos: Ali Sarkhosh, UF/IFAS

\section{Maduración}

La temporada de cosecha de fruta de caqui astringente ocurre justo antes y durante de la etapa blanda del desarrollo de la fruta. Si se recoge durante este tiempo, la fruta es blanda o se ablandará, y los taninos astringentes se coagulan, haciendo que la fruta sea adecuada para el consumo. Generalmente, la fruta se puede recoger y ablandar a temperatura ambiente unos 7 a 10 días antes de que se ablande en el árbol. El tiempo varía ligeramente con el cultivar y es aproximadamente el mismo para cultivares astringentes y no astringentes. No todas las frutas en el árbol llegan a dicha etapa al mismo tiempo. El proceso de ablandamiento será menos eficaz y tardará más en producirse cuanto antes se recoja la fruta.

Elegir la temporada de cosecha adecuada para los caquis no astringentes es menos complicado que para los cultivares astringentes porque estos últimos se pueden comer cuando la pulpa es firme. Los taninos astringentes se descomponen más temprano en el período de desarrollo - en un momento 
en que la fruta está todavía dura. Son más fáciles de cosechar, almacenar y comercializar que los cultivares astringentes y son muy populares en muchas partes del mundo. Las frutas se cosechan por color y pueden ser calificadas como maduras con ayuda de una carta de colores. La eliminación del verde por el creciente desarrollo de amarillo y/o naranja a naranja-rojo es una indicación general de fruta comercializable.

El ablandamiento y la eliminación de astringencia pueden inducirse cubriendo la fruta con arroz seco sin cocinar durante 3-5 días. Congelar la fruta por 24 horas tendrá resultados similares. El gas etileno se puede utilizar para acelerar el proceso de maduración y desarrollar más color de fruta.

Daños ambientales, como lesiones por aves o por viento, e imperfecciones de la fruta, como grietas en la punta, separaciones de cáliz o anillos de crecimiento apical, también inducirán el ablandamiento. Generalmente, cuanto más lejos del estado blando esté el fruto cuando se producen las aberturas o divisiones, más localizada será el área de maduración en la fruta. Con el agrietamiento de los anillos de crecimiento y rajaduras en la punta, la fruta madura y desarrolla color desde el extremo apical hacia arriba, mientras que ocurre lo contrario en las separaciones del cáliz.

\section{Comercialización y uso}

La ventana para mercadeo de caquis frescos es de septiembre a diciembre. La comercialización directa a través de los mercados de agricultores, los puestos de venta en granjas y las operaciones de "cosecha tu propia fruta" son métodos comunes para comercialización de caquis (Figura 2). Los caquis de tipo astringente pueden ser difíciles de comercializar. Muchos frutos de caqui astringente comercializados en California, aunque atractivos a la vista, han sido cosechados muy temprano. Esto no permite que la fruta pierda su astringencia sin tratamiento, lo que significa una experiencia desagradable para los consumidores, haciendo difícil que vuelvan a consumir caquis. En Japón, para eliminar la astringencia, la fruta se rocía con un 35\%-40\% de alcohol etílico y se coloca en un recipiente sellado durante 10 días a $69^{\circ} \mathrm{F}$. El producto es un fruto firme de buena calidad, que se comercializa fácilmente, y se ablandará rápidamente.

Mayor educación a clientes sobre el proceso de maduración de caquis astringentes y sobre las características de los diferentes cultivares podría ayudar a la comercialización, al igual que ofrecer muestras en las tiendas para captar potenciales clientes. Producir más cultivares no astringentes también sería beneficioso. Una evaluación sensorial de los consumidores realizada en 1997 utilizando el cultivar no astringente 'Fuyu' encontró que el 51\% de los participantes nunca habían probado caqui antes, y que la mayoría de los participantes se sorprendieron y disfrutaron de la experiencia, incluyendo aquellos que normalmente consumían cultivares astringentes. Con una población estimada de más de 21 millones de habitantes, una base cultural diversa y grandes ciudades cercanas a las zonas de producción, Florida está preparada para una expansión de la industria del caqui.

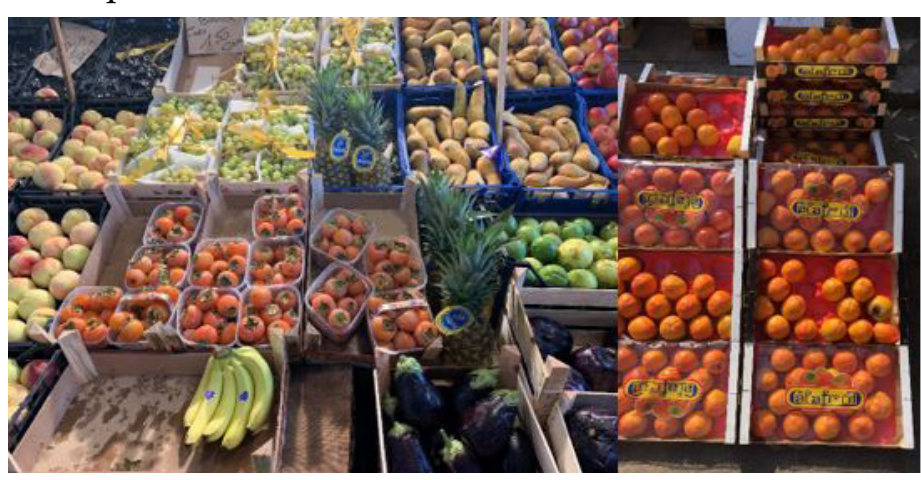

Figura 2. Caqui astringente (izquierda) y no astringente (derecha) en un supermercado local en Palermo, Sicilia, Italia en 2019. Créditos: Ali Sarkhosh, UF/IFAS

En los Estados Unidos, el destino ideal de caquis astringentes es el consumo doméstico, el secado y las operaciones de "cosecha tu propia fruta". En los hogares de Asia oriental, los frutos del árbol de caqui en el jardín familiar son pelados, colocados en un pincho, y colgados para secar. Las frutas secas son dulces y deliciosas, con el azúcar generalmente cristalizada en la superficie del fruto, haciendo el producto blanco y atractivo. La cáscara seca se utiliza como un producto para teñir. En Florida, el secado al sol de la fruta cortada a la mitad o en rodajas en una cámara de vidrio o polietileno, o en una secadora comercial de alimentos (proceso "regular" de secado-deshidratación), genera un producto delicioso y listo en 3 a 7 días. El fruto puede ser fumigado con azufre para una mejor apariencia y almacenamiento. El secado elimina naturalmente toda astringencia.

$\mathrm{La}$ fruta no astringente es buena para comer fresca y es excelente combinada con peras, dátiles, manzanas, cítricos, pasas y/o coco en ensaladas. Tienen claras ventajas de mercadeo y manejo porque se pueden cosechar antes $y$ tienen una vida útil más larga. Su aceptación por parte de los consumidores es mayor porque no tiene que ser consumido en un estado "pegajoso-aguado", lo que es objetable para muchas personas. Para extender su alcance a otros mercados, la fruta también se puede procesar para generar productos horneados y botanas. Debido a que los caquis 
tienen relativamente pocos problemas de plagas, la producción orgánica de la fruta podría abrir otra vía de mercado.

\section{Almacenamiento}

Generalmente, debido a que los caquis astringentes deben ser blandos o cercanos a ese estado durante la cosecha, no son fáciles de almacenar; sin embargo, los cultivares no astringentes se pueden almacenar hasta durante 30 días a temperatura ambiente. Los colores aumentarán un poco, el contenido de azúcar seguirá igual, y el peso disminuirá de un $7 \%$ a $10 \%$. Sólo la fruta sin imperfecciones se almacena bien durante un largo período. Generalmente, los cultivares de maduración temprana, como 'Izu', tienen una vida útil más corta que cultivares de maduración tardía, como 'Fuyu'. En Japón, la fruta se envuelve individualmente en polietileno fino y se almacena a $32^{\circ} \mathrm{F}$ durante $4-5$ meses. El fruto seguirá siendo de buena calidad cuando se retire del almacenamiento.

\section{Azúcares}

El porcentaje de sólidos o azúcares solubles aumenta para ambos tipos de caquis a medida que el fruto se acerca a la etapa blanda de maduración en el árbol. Los azúcares, medidos como sólidos solubles, promedian un 15\% a $20 \%$ en frutos no astringentes. Generalmente, los niveles de azúcar en frutos astringentes son ligeramente más altos, alcanzando incluso el $24 \%$ en cultivares de maduración tardía. La fructosa y la glucosa conforman el $90 \%$ del total de azúcares, y la sacarosa también está presente pero en menor proporción.

\section{Textura}

La textura de la pulpa de la fruta blanda astringente y no astringente varía considerablemente. Algunos frutos como 'Saijo' son jugosas, con una alta consistencia de gelatina en la pulpa y un aspecto translúcido, de color naranja oscuro. Otros frutos como 'Great Wall' y 'Tanenashi' son pastosos, algo secos, y opacos. Los frutos no astringentes son de la mejor calidad cuando están crujientes como una manzana con pulpa jugosa, de color naranja y una pequeña zona gelatinosa dentro y alrededor de los carpelos. Algunos cultivares son filamentosos con fibras que se unen al cáliz y siguen una orientación vertical alrededor de la sección del carpelo hacia el extremo apical. Es evidente cuando estos frutos están suaves y maduros. El espesor de la cáscara también varía entre cultivares; 'Hiratanenashi' tiene una cáscara gruesa, 'Tanenashi’ una cáscara media, y ‘Saijo’ una cáscara relativamente delgada.

\section{Imperfecciones fisiológicas de la fruta}

El trastorno fisiológico más común de la fruta de tipo astringente ocurre en cultivares de fruto cónico o redondo. El trastorno consiste en anillos de crecimiento concéntricos que aparecen como pequeñas líneas oscuras alrededor del extremo apical de la fruta. La maduración desigual se produce cuando estos anillos se parten en las etapas posteriores del desarrollo de la fruta.

La separación del cáliz de la sección de la pulpa del fruto es un trastorno que aparece con mayor frecuencia en frutos de tipo no astringente. Una cavidad se desarrolla en el fruto a medida que el cáliz deja de crecer, alrededor de julio, mientras que la sección de la pulpa continúa agrandándose hasta la cosecha. La cavidad se forma en un lado del cáliz y causa maduración desigual, almacenamiento deficiente y genera un área propensa al ingreso de enfermedades infecciosas. Los frutos que tienen un cáliz grande en relación con el tamaño del fruto en el momento de la floración son menos propensos a desarrollar el trastorno.

Rajaduras en el extremo apical de la fruta generalmente se observan en cultivares de fruto grande, principalmente no astringentes. Las rajaduras se agrandan y agrietan durante el último mes de maduración. Se forman porque la fusión de la base del estigma durante la floración y el desarrollo temprano es incompleta. Este trastorno es específico de acuerdo con el cultivar.

\section{Temporada de producción de fruto}

La época de cosecha, especialmente para los tipos no astringentes cultivados comercialmente, es generalmente la etapa más temprana, cuando el cultivo tiene suficiente color para ser comercializado. Los frutos pueden permanecer en el árbol un mes más, volviéndose más suaves, con mayor color y contenido de azúcar. Sin embargo, dejar madurar el fruto en el árbol tiene una consecuencia. Frutos maduros son muy susceptibles al daño por insectos, pequeños mamíferos (mapaches y zarigüeyas) y cuervos. Defoliación temprana en otoño retrasará y en algunos casos cesará la maduración de frutos. El cultivar del portainjertos, y ciertas condiciones fisiológicas y ambientales, también pueden afectar los tiempos de maduración.

\section{Dimensiones del Fruto y Árbol de Caqui}

\section{Forma del fruto}

Las tres formas más comunes del fruto son: cónicos (en forma de cono), redondos (redondas y a veces puntiagudas 
en el ápice como una bellota), y oblatos (aplanadas como un tomate común) (Figura 3). Algunos cultivares tienen características notables, como un anillo con una división alrededor del fruto en los cultivares 'Midia' y 'Tamopan'. Cuatro lados a veces son evidentes en el fruto de 'Great Wall' o 'Saijo'. Secciones lobuladas diferentes están presentes en 'Sheng' y 'Peiping. Los frutos de algunos cultivares están metidos o plegados en el cáliz, como 'Suruga'.

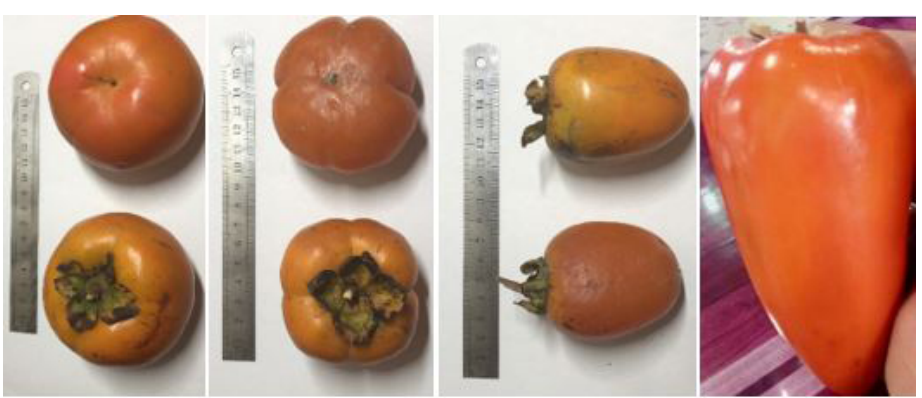

Figura 3. Diferentes formas de fruto de distintos cultivares de caqui. Créditos: Ali Sarkhosh, UF/IFAS

\section{Tamaño del fruto}

El tamaño del fruto se ve afectado por la cantidad de fruto en la planta. Cuando menor la cantidad de frutos, mayor será el tamaño de estos. Frutos pequeños generalmente pesan entre $3.5 \mathrm{oz}(100 \mathrm{~g})$ a $4.5 \mathrm{oz}(130 \mathrm{~g})$, frutos medianos entre $5.5 \mathrm{oz}(150 \mathrm{~g})$ a $7.0 \mathrm{oz}(200 \mathrm{~g})$, y frutos grandes entre 8 $\mathrm{oz}(230 \mathrm{~g})$ a $14 \mathrm{oz}(400 \mathrm{~g})$ (Figura 4$).$
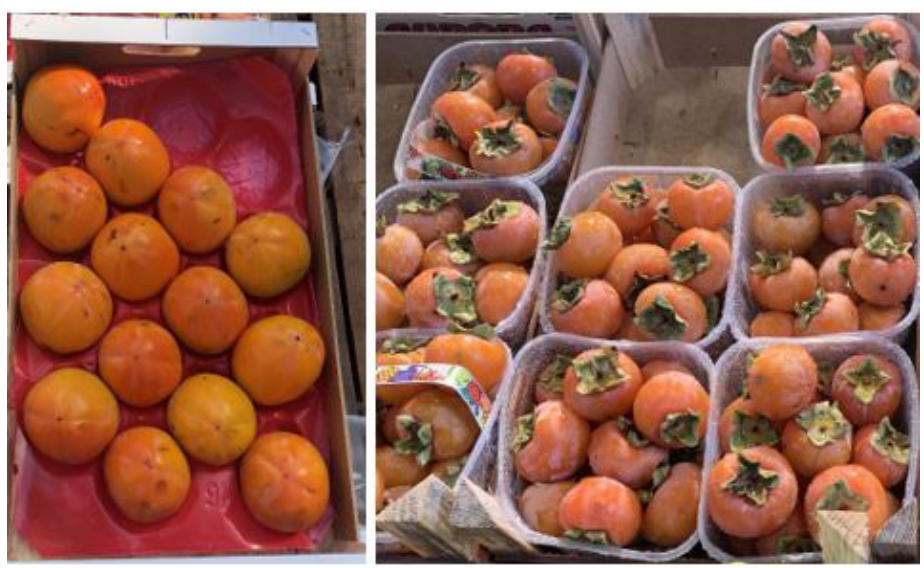

Figura 4. El tamaño y peso del fruto en el caqui puede variar de acuerdo al cultivar, desde 3,5 oz (100 g) a 14 oz (400 g).

Créditos: Ali Sarkhosh, UF/IFAS

\section{Tamaño y forma del árbol}

Las plantas semi enanas alcanzan una altura de entre 6 a 8 pies, y tienen copa redondeada (Figura 5). 'Makawa Jiro' y 'Ichikikei-Jiro' son ejemplos de este tipo. Los árboles de tamaño medio tienden a ser más altos con brotes más verticales. Sus ramas generalmente se extienden con cargas de fruta. La mayoría de los árboles de caqui caen en esta categoría. Los árboles considerados altos son verticales y a menudo producen frutos pequeños. Generalmente, el tamaño del árbol se reduce entre el sur de Gainesville y el sur de Florida. Se ha observado que los árboles cultivados en Florida son a menudo más pequeños de lo que se esperaría en su lugar de origen; cultivares comunes apenas alcanzaron 10 pies de altura después de 10 años en ensayos durante la década de 1960.

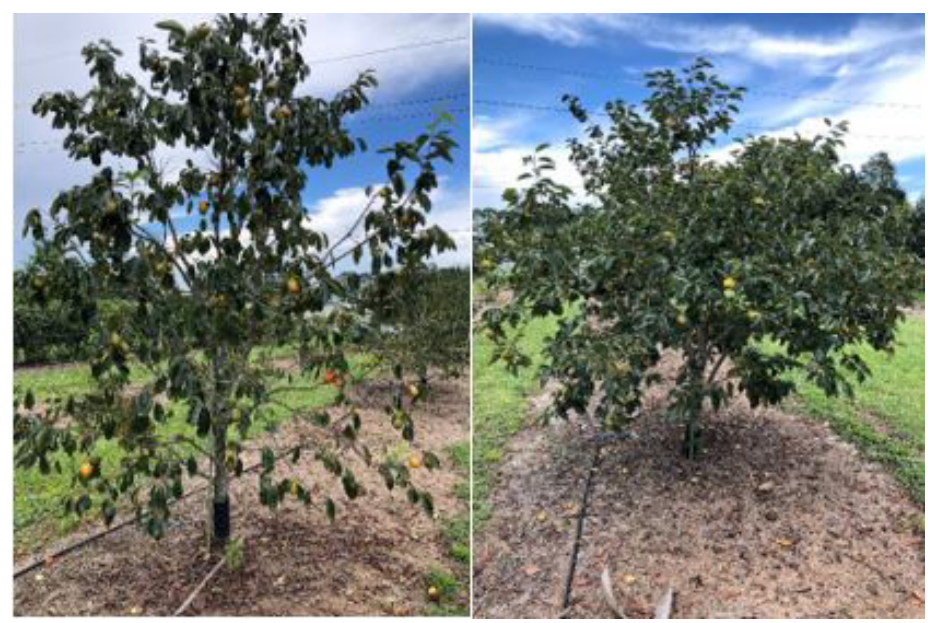

Figura 5. Tamaño y forma puede variar entre los cultivares 'Saijo' (izquierda) y'Fuyu' (derecha).

Créditos: Ali Sarkhosh, UF/IFAS

\section{Descripciones de Algunos Cultivares No Astringentes}

\section{Cultivares tempranos}

'Izu' tiene la distinción de ser el cultivar no astringente de maduración más temprana (Figura 6). El vigor del árbol es muy bajo y no es precoz. El tamaño del fruto es mediogrande, y los sólidos solubles promedian el 16\%. La forma del fruto es oblata y un porcentaje considerable muestra imperfecciones. La temporada de cosecha comienza a finales de septiembre y termina a mediados de noviembre. A veces se recomienda 'Izu' debido a su maduración temprana.

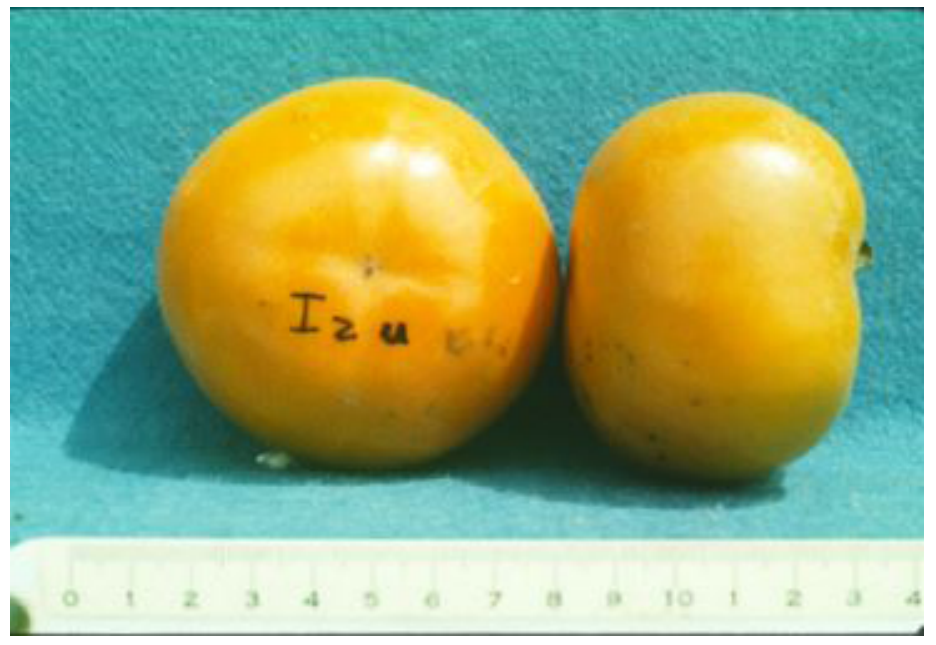

Figura 6. Cultivar 'Izu'.

Créditos: Departamento de Ciencias Hortícolas, UF/IFAS 


\section{Cultivares medios}

'Matsumoto Wase Fuyu' es un porte de maduración temprana de 'Fuyu' (Figura 7). Este árbol desarrolla muchas flores y produce grandes cargas de frutos agrupados. Los racimos deben podarse para evitar ramas dobladas con cargas excesivas de fruta. Los frutos más grandes son propensos a la separación del cáliz. El árbol es moderadamente vigoroso y de tamaño medio. Los sólidos solubles oscilan entre el $16 \%$ y el $19 \%$, lo que generalmente ocurre con la mayoría de los cultivares medios de caqui. El fruto es de tamaño mediano y de forma oblata. La tendencia a que la fruta sufra agrietamiento de la punta es poca o nula.

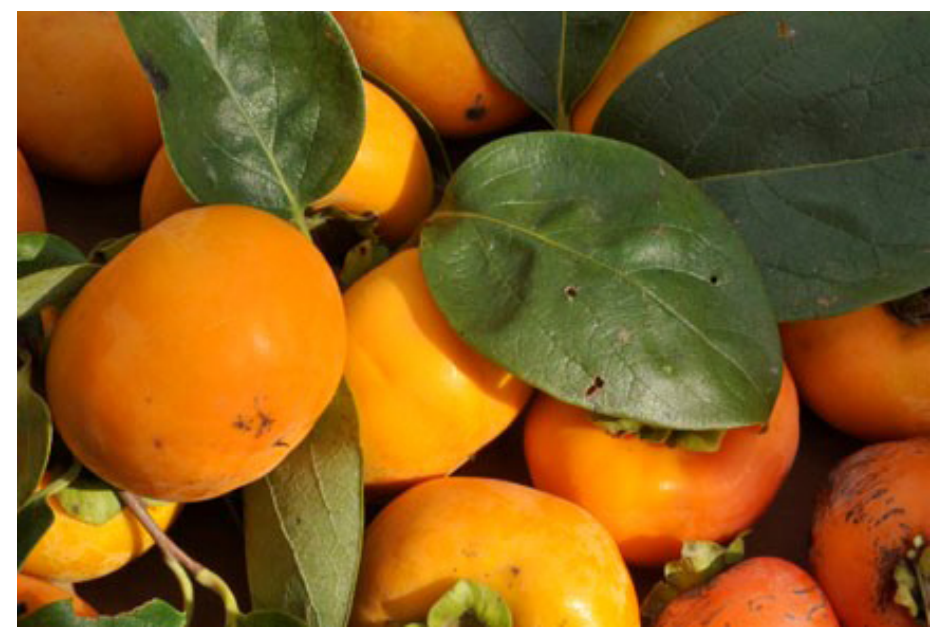

Figura 7. Cultivar 'Matsumoto Wase Fuyu'. Créditos: Edible Landscaping LLC

'Ichikikei Jiro' es un porte de yema de 'Jiro' de vigor bajo a moderado (Figura 8). Florece más tarde que la mayoría de los cultivares de caqui. El tamaño del fruto es de medio a grande con sólidos solubles de 16\% a 19\%. Algunos frutos sufren el agrietamiento de la punta. Los frutos tienen forma oblata. La temporada de cosecha es de mediados de octubre a mediados de noviembre. 'Ichikikei Jiro' se recomienda para el norte y centro-norte de Florida.

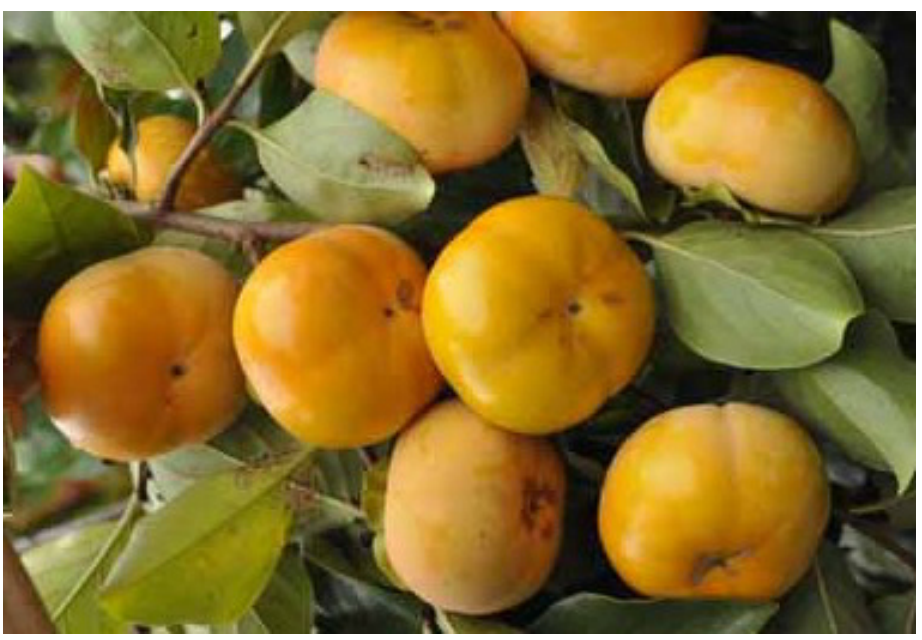

Figura 8. Cultivar 'Ichikikei Jiro'.

Créditos: Edible Landscaping LLC
'Jiro' es un árbol de vigor moderado. La producción de frutos puede ser errática cuando los árboles son jóvenes, pero el rendimiento es más consistente en árboles más viejos (Figura 9). El tamaño del fruto es de mediano a grande, los sólidos solubles oscilan entre $16 \%-19 \%$, y la forma del fruto es oblata. La punta del fruto puede agrietarse. La temporada de cosecha es de mediados de octubre hasta mediados de noviembre. 'Jiro' es un cultivar recomendado.

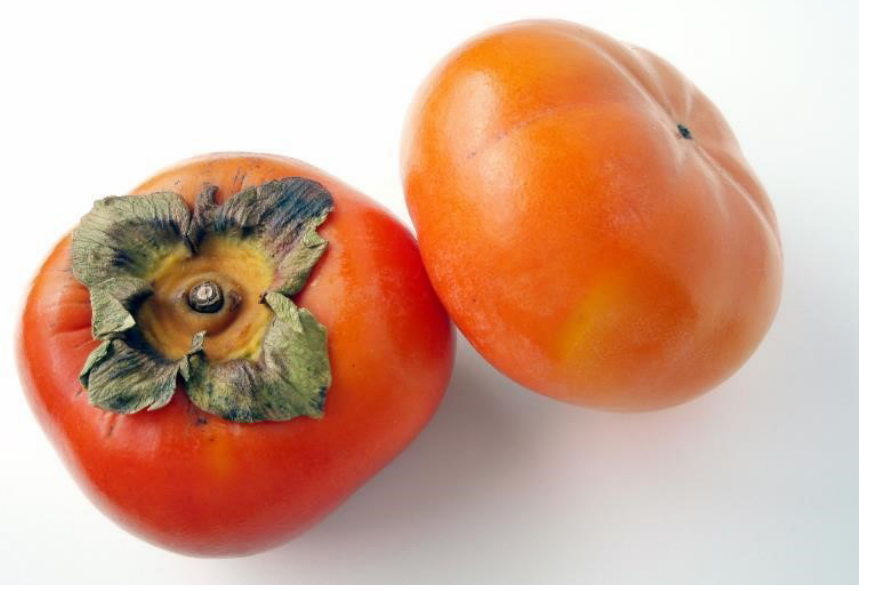

Figura 9. Cultivar 'Jiro'.

Créditos: Edible Landscaping LLC

'Maekawa Jiro', un porte de yema 'Jiro', es de vigor bajo a moderado (Figura 10). El tamaño del fruto es grande, y su forma es oblata. Hay cierta tendencia a que la fruta sufra agrietamiento de la punta. La temporada de cosecha es de mediados de octubre a mediados de noviembre. 'Makawa Jiro' no se recomienda para el norte y centro-norte de Florida.

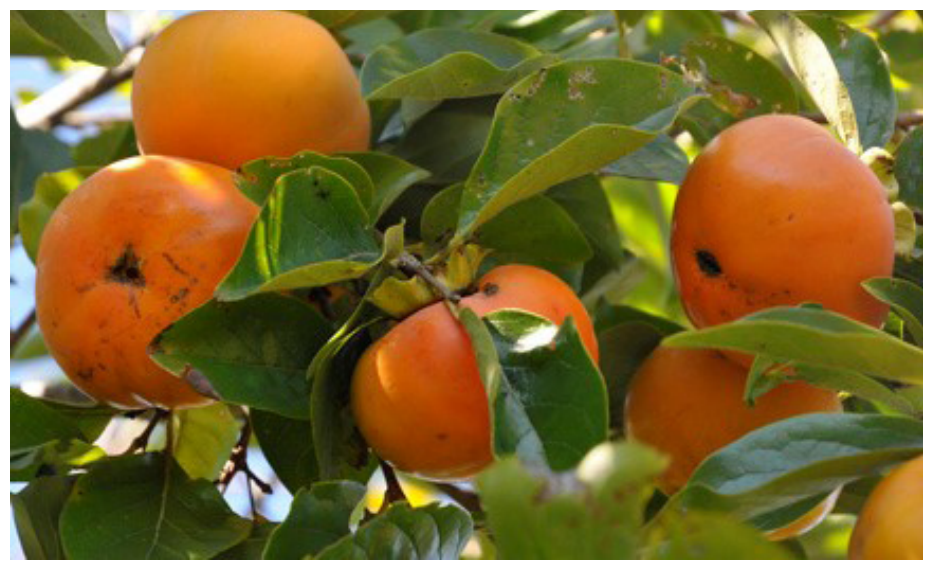

Figura 10. Cultivar 'Makawa Jiro'.

Créditos: Edible Landscaping LLC

'Midia' es un cultivar de árboles de vigor moderado, pero más susceptibles a decaimiento que la mayoría de otros caquis japoneses (Figura 11). El cuaje de frutos y retención de la fruta hasta la cosecha no es consistentemente alto. 'Midia' produce el fruto más grande de todos los cultivares de caqui no astringente. La forma de la fruta es redonda 
con un anillo divisorio alrededor de la parte superior de la fruta. La temporada de cosecha es de finales de octubre a mediados de noviembre. 'Midia' no se recomienda para el norte o centro-norte de Florida.

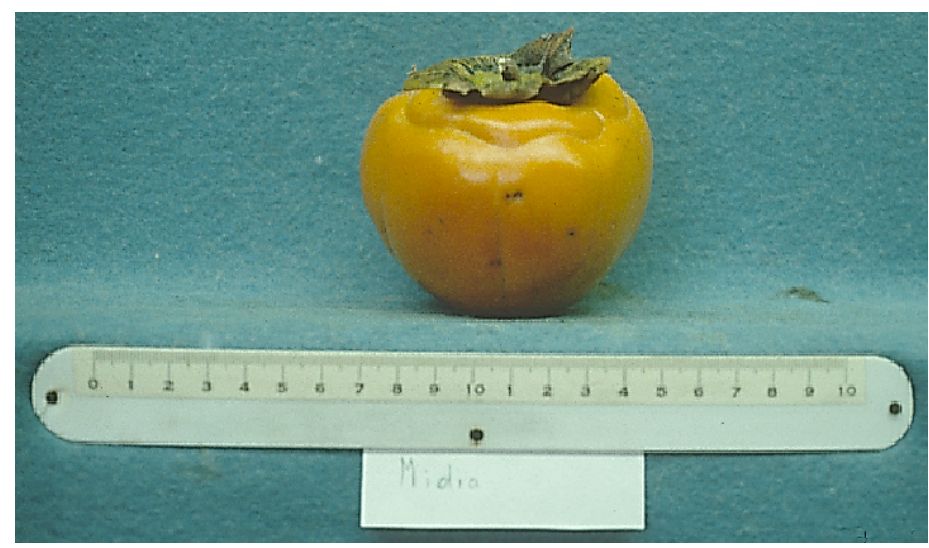

Figura 11. Cultivar 'Midia'.

Créditos: Departamento de Ciencias Hortícolas, UF/IFAS

'Hana Fuyu', también conocido como 'Yotsundani' o 'Giant Fuyu', regula bien las cargas de fruto y es de vigor medio (Figura 12). El fruto es ligeramente más grande que la mayoría de caquis, generalmente están libres de imperfecciones, y pueden demorar en perder su astringencia. Este cultivar es bueno para los jardines caseros.

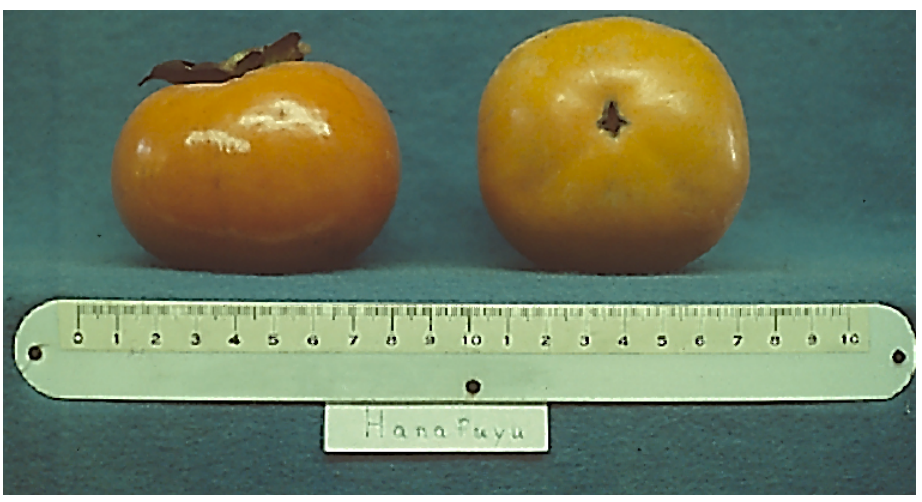

Figura 12. Cultivar 'Hana Fuyu'.

Créditos: Departamento de Ciencias Hortícolas, UF/IFAS

'Hanagosho' es un árbol grande con un crecimiento vertical vigoroso y una distribución de ramas fuerte (Figura 13). El árbol generalmente produce una pequeña cantidad de floración masculina cada año, y la regulación de la carga de fruto en el árbol es buena. El fruto y las hojas son ligeramente más susceptibles a los patógenos de temporada tardía que la mayoría de otros cultivares. 'Hanagosho' es un árbol grande y bueno para cultivar en el jardín de casa.

'Shogatsu' es similar a 'Hanogosho' en el hábito de crecimiento; sin embargo, tiene más problemas con rajaduras en el extremo de la fruta y manchas en las hojas (Figura 14).

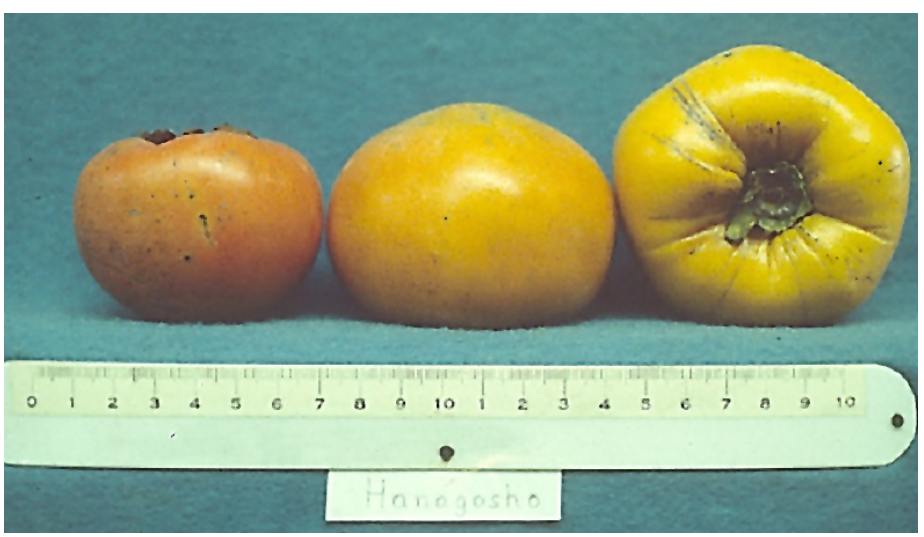

Figura 13. Cultivar 'Hanagosho'.

Créditos: Departamento de Ciencias Hortícolas, UF/IFAS

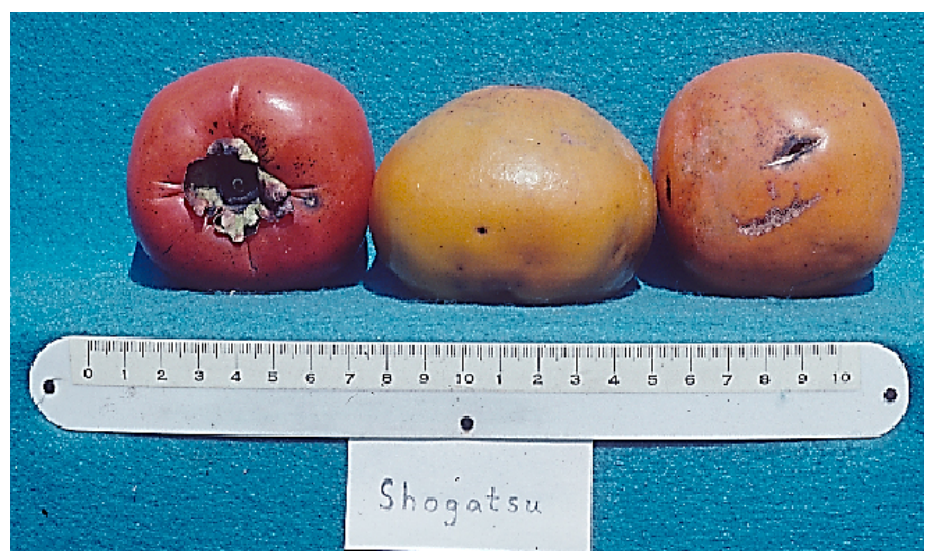

Figura 14. Cultivar'Shogatsu'.

Créditos: Departamento de Ciencias Hortícolas, UF/IFAS

\section{Cultivares tardíos}

'Fuyu', también conocido como 'Fuyugaki', es el cultivar no astringente más popular en Florida y es el árbol de caqui más ampliamente cultivado en el mundo. Tiene cuatro lados y es firme cuando está maduro, con muy pocas semillas (Figura 15). Por lo general, la reducción de la carga de frutos es necesaria para garantizar producción de frutos grande, evitar la formación de racimos y regular la carga de fruto en la planta. La incidencia de imperfecciones en fruta es baja, los rendimientos son buenos, y el árbol está generalmente bien adaptado, con un promedio de sólidos solubles del 18\%. Existen muchos cultivares diferentes con el nombre 'Fuyu' o 'Fuyugaki'. La forma del fruto es oblata y pocas frutas muestran imperfecciones. La temporada de cosecha es de mediados de noviembre hasta principios de diciembre. 'Fuyu' es muy recomendable para el centro y centro-norte de Florida.

'Suruga' es un cultivar de árboles de vigor moderado (Figura 16). Producen fruta de maduración tardía que es excepcionalmente dulce (sólidos solubles entre 18\%-21\%). La forma de su fruto es clasificada como oblata cónica, y las imperfecciones en frutos son bastante comunes. El tamaño de la fruta es de mediano a grande. La temporada 
de cosecha es de finales de noviembre a principios de diciembre. Parece ser susceptible a defoliación prematura. 'Suruga' no es recomendado para producción comercial.

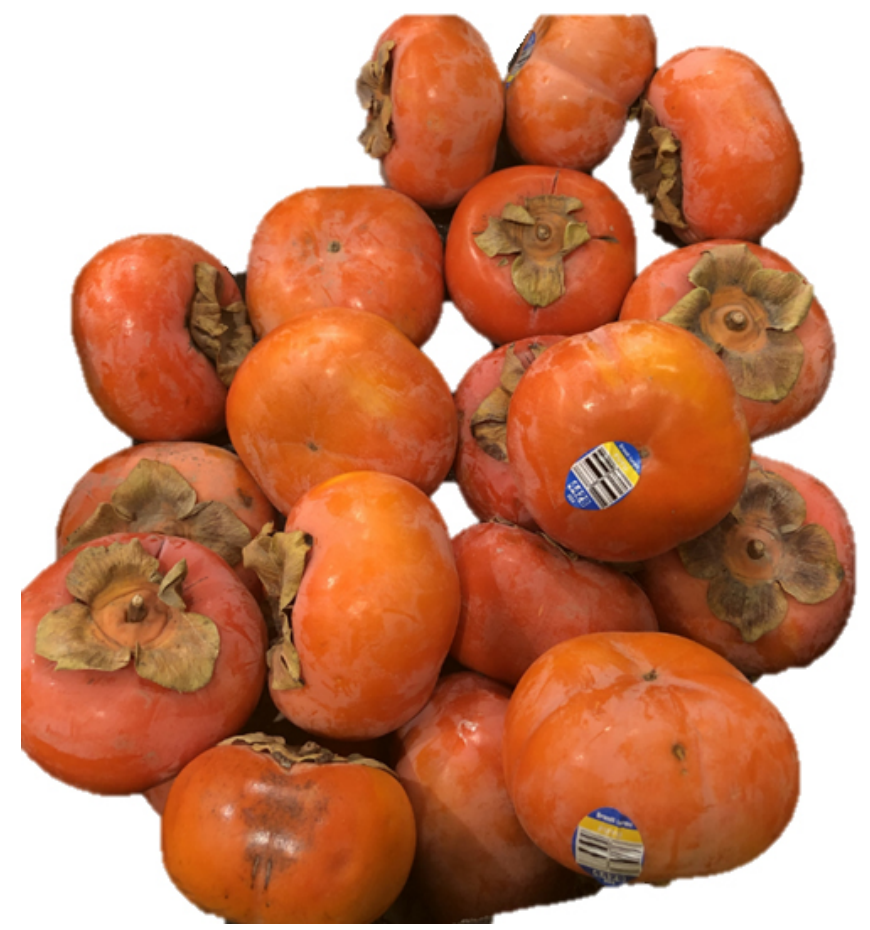

Figura 15. Cultivar 'Fuyu'.

Créditos: Ali Sarkhosh, UF/IFAS

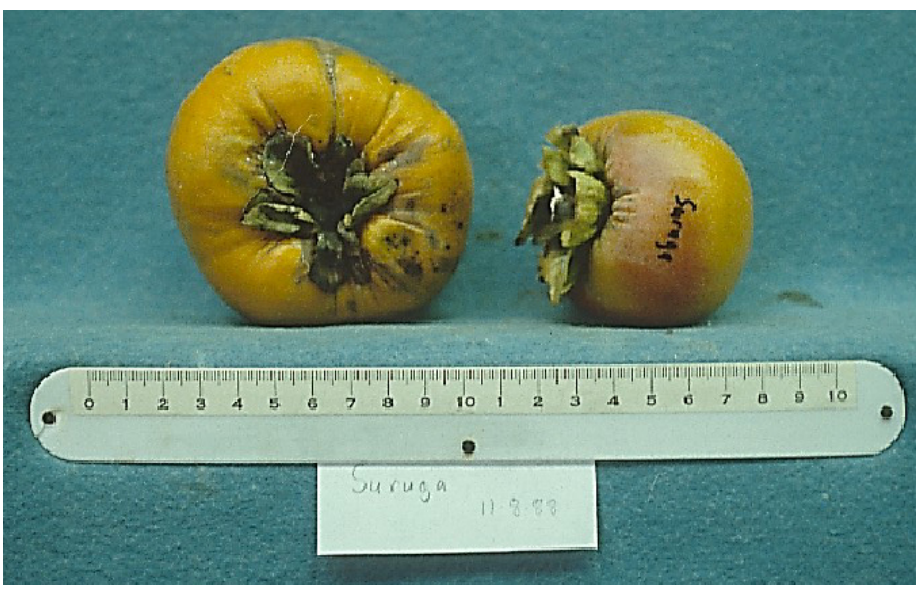

Figura 16. Cultivar 'Suruga'.

Créditos: Departamento de Ciencias Hortícolas, UF/IFAS

\section{Cultivares Comerciales no}

\section{Astringentes Recomendados}

Las plantaciones de caquis no astringentes se pueden establecer para incluir cultivares cuyos frutos madurarán desde finales de septiembre hasta principios de diciembre. Los cultivares recomendados parecen producir el porcentaje más alto de fruta comercializable. 'Izu' es la elección para la temporada temprana, 'Matsumoto Wase Fuyu' para la mitad de la temporada, y 'Fuyu' para la temporada tardía. 'Fuyu' es el que está disponible más fácilmente y generalmente se considera el mejor cultivar comercial no astringente en Florida.

\section{Descripciones de Algunos Cultivares Astringentes \\ Cultivares tempranos}

'Nishumura Wase' es un cultivar temprano, su primer fruto madura a principios de agosto (Figura 17). Es una variante de polinización y debe producir semillas para ser no astringente. Desarrolla flores masculinas constantemente. El fruto es algo acuoso y tiene alrededor del 13\% al 15\% en sólidos solubles. El árbol tiene buena distribución de la copa, es algo vigoroso y su rendimiento anual es bueno.

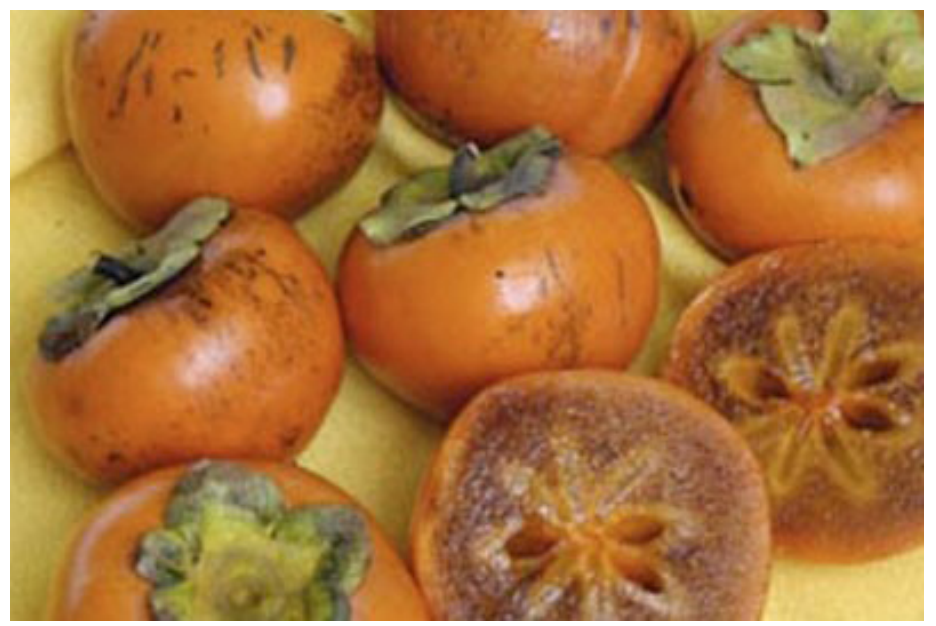

Figura 17. Cultivar 'Nishumura Wase'.

Créditos: Sperling Nursery and Gift Shop

'Saijo' es considerado uno de los caquis más dulces, aunque a veces quedan rastros de astringencia cuando el fruto es blando (Figura 18). El fruto madura entre el inicio y la mitad de la temporada. Estos frutos son relativamente pequeños, con una forma cónica larga y una pulpa gelatinosa de color naranja y translúcido. Los sólidos solubles oscilan entre el $16 \%$ y el $22 \%$. El árbol 'Saijo' es grande, erguido y vigoroso, capaz de producir grandes rendimientos. Es un buen cultivar para los jardínes caseros.

'Giombo' es similar a 'Saijo' en la calidad del fruto, aunque este es mucho más grande y comienza a madurar dos semanas más tarde (Figura 19). Los frutos son de color naranja ligeramente translúcidos, de cáscara delgada, con una pulpa dulce, jugosa y gelatinosa. El fruto de 'Giombo' sería la elección de un conocedor. El árbol inicia su crecimiento temprano en la primavera y a veces puede sufrir daños por temperaturas muy bajas. 


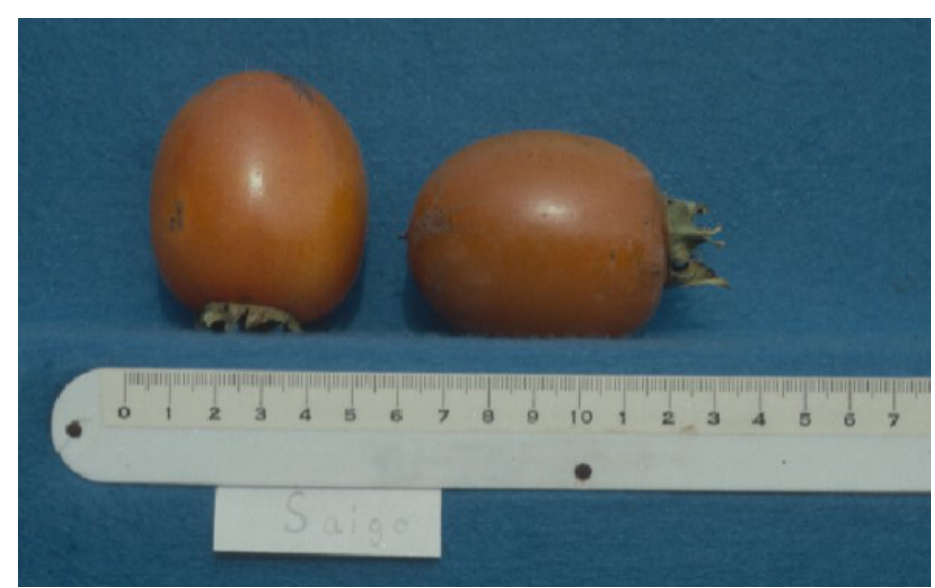

Figura 18. Cultivar 'Saijo'.

Créditos: Departamento de Ciencias Hortícolas, UF/IFAS

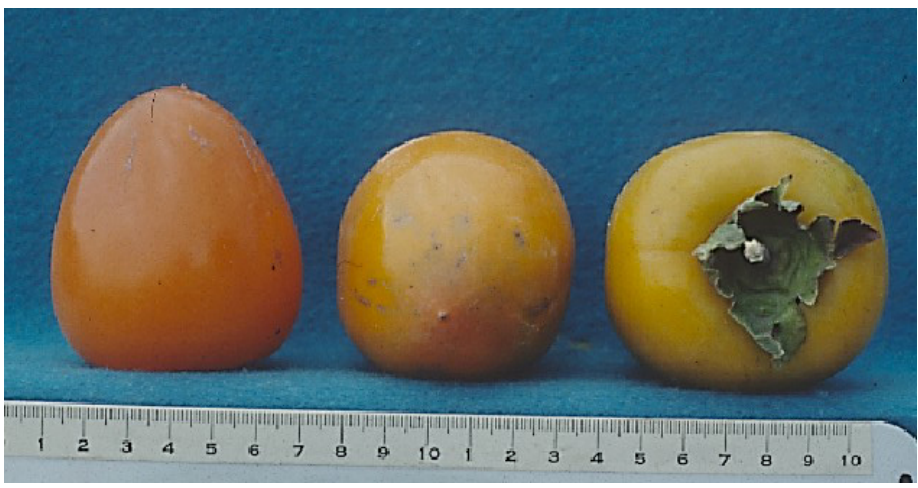

Figura 19. Cultivar 'Giombo'. Crédito de la fotografía:

Créditos: Departamento de Ciencias Hortícolas, UF/IFAS

\section{Cultivares medios}

'Eureka' ha sido ampliamente propagado por los viveros del sur y es un cultivar común en Texas (Figura 20). Tienes frutos grandes, redondeados, achatados, de polinización variante, con una cantidad media de pulpa oscura alrededor de la semilla.

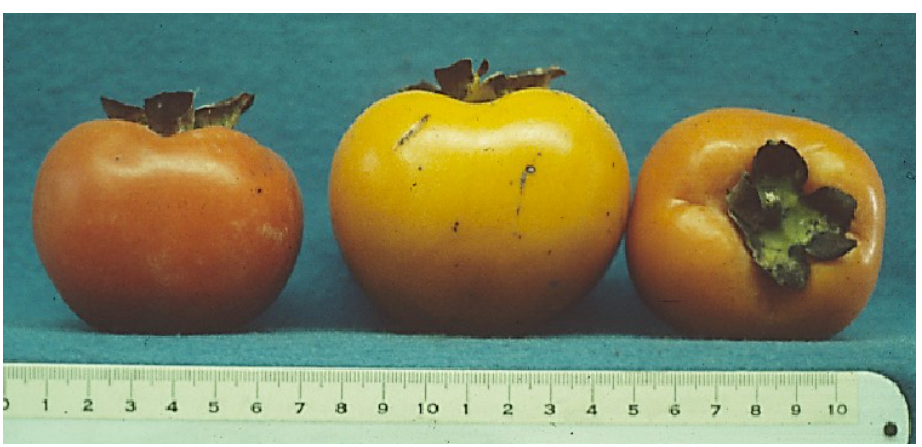

Figure 20. Cultivar 'Eureka'.

Créditos: Departamento de Ciencias Hortícolas, UF/IFAS

'Sheng' es un árbol de buena distribución de copa, que produce grandes frutos con secciones lobuladas que parecen tener forma de trébol de 4 ó 6 hojas cuando son vistos desde arriba (Figura 21). El fruto tiene un alto contenido de pulpa gelatinosa, son de color naranja brillante, y cuando es polinizado produce muchas semillas.

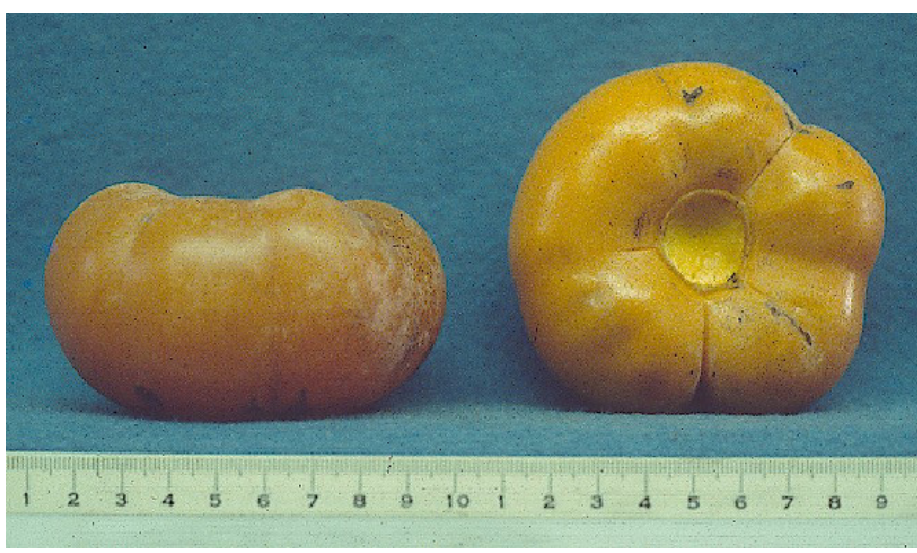

Figura 21. Cultivar 'Sheng'. Crédito de la fotografía: Créditos: Departamento de Ciencias Hortícolas, UF/IFAS

'Yomato Hyakume' es un cultivar de polinización variante, pero no tiene una gran cantidad de pulpa oscura alrededor de las semillas. El fruto es grande, con un color rojo anaranjado profundo (Figura 22). A menudo, se produce un agrietamiento concéntrico del anillo. Este cultivar es un gran productor anual con buena retención de hojas en otoño. Es excelente para frutos secos y es uno de las mejores cultivares astringentes.

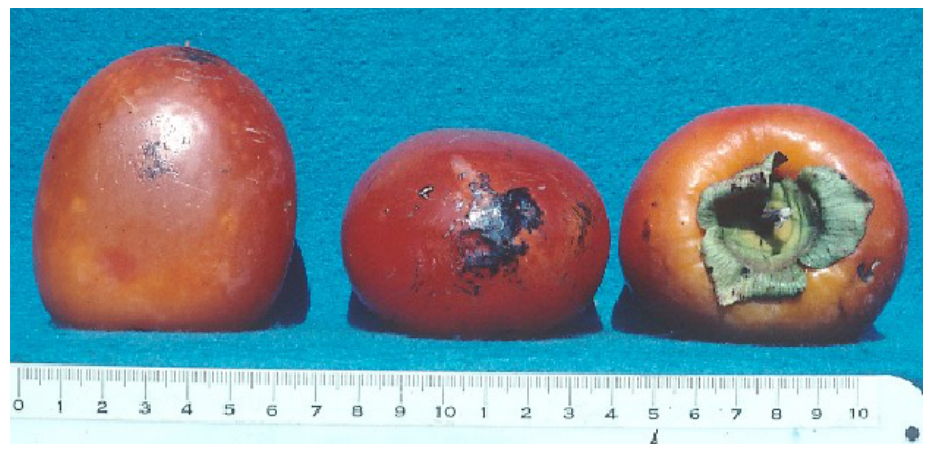

Figura 22. Cultivar'Yomato Hyakume'.

Créditos: Departamento de Ciencias Hortícolas, UF/IFAS

'Tanenashi', el cultivar astringente más popular en Florida, produce importantes cargas de fruto en el árbol sin polinización, y rara vez produce semillas incluso si se poliniza (Figura 23). Por lo general, es deseable reducir la cantidad de fruta para obtener algo de crecimiento vegetativo durante el año. El fruto, a menudo grande ( $3 \frac{1}{2}$ " de ancho), puede pesar más de $3 / 4$ de libra. El color de la cáscara es amarillo profundo a naranja cuando madura. La pulpa es naranja, pastosa, relativamente seca y de calidad aceptable. Los sólidos solubles promedian el 16\%. La duración de la cosecha puede extenderse de septiembre a noviembre. Es una buen cultivar para los jardínes caseros.

'Hachiya' es un cultivar comercial en California (Figura 24). La capacidad de cuajar y retener el fruto es a veces un problema si este cultivar se propaga sobre el portainjerto Diospyros virginiana. El fruto es de alta calidad y la pulpa gelatinosa, con una cáscara roja bastante atractiva. El fruto 
a menudo sufrirá de agrietamiento de anillo concéntricos en el extremo apical y madurará de manera desigual a partir de estas zonas. En Japón, 'Hachiya' es mayormente utilizado para producir fruta seca. La astringencia del fruto permanece hasta que esté ha madurado completamente y se ablanda.

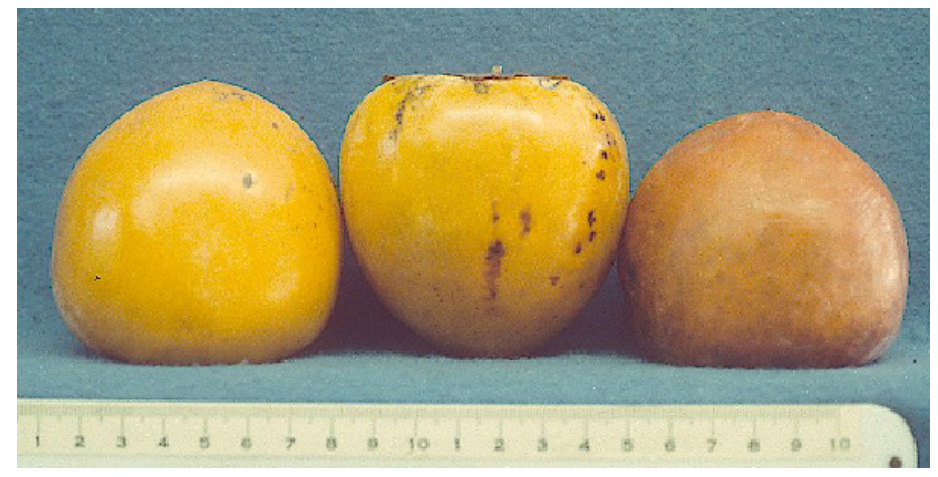

Figura 23. Cultivar 'Tanenashi'.

Créditos: Departamento de Ciencias Hortícolas, UF/IFAS

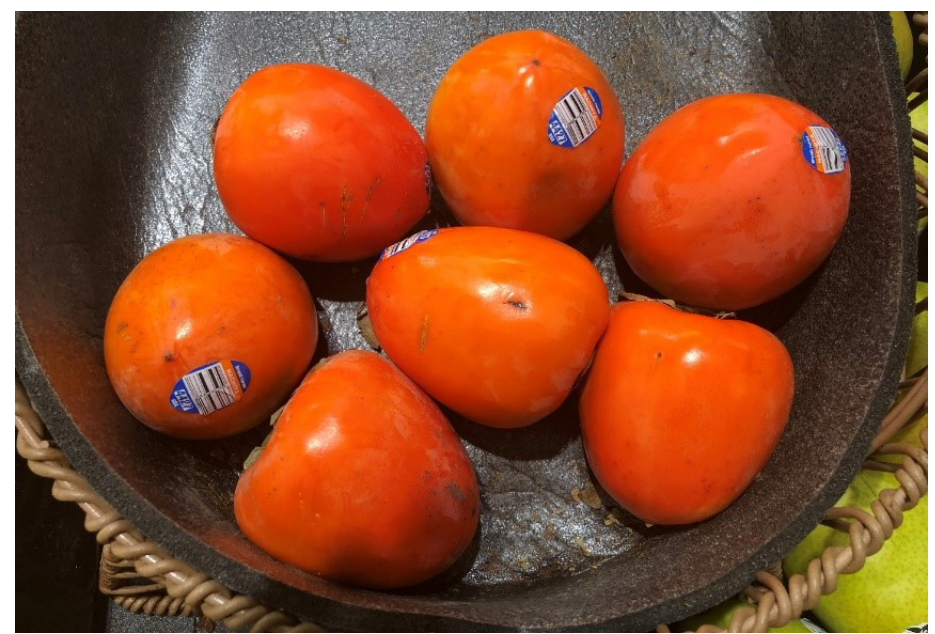

Figura 24. Cultivar 'Hachiya'.

Créditos: Ali Sarkhosh, UF/IFAS

'Hiratanenashi' es un cultivar comercial ampliamente producido en Japón (Figura 25). El fruto tiene una cáscara gruesa y una larga vida útil. La pulpa es jugosa, algo acuosa, y casi siempre no tiene semillas. La astringencia a veces es difícil de eliminar después de que el fruto ha sido cosechado, a menos que sean tratados artificialmente.

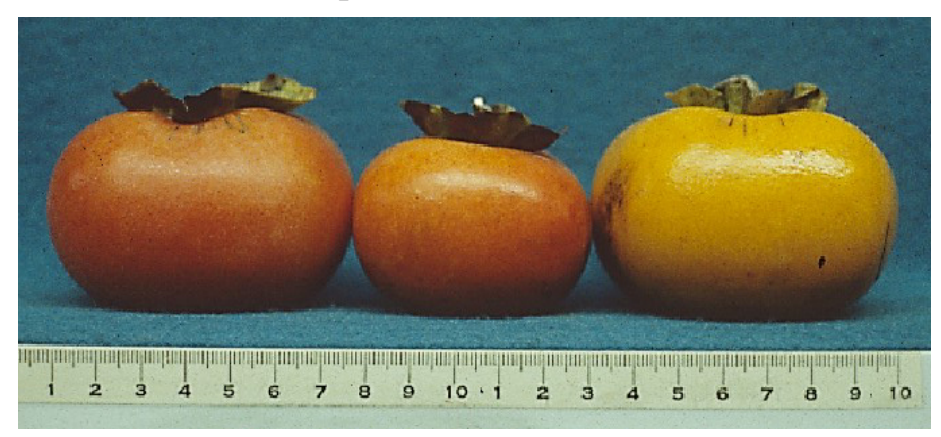

Figura 25. Cultivar 'Hiratanenashi'.

Créditos: Departamento de Ciencias Hortícolas, UF/IFAS
'Great Wall' es un cultivar de crecimiento vigoroso, de frutos pequeños con cuatro secciones (Figura 26). La pulpa es seca, similar a la de los frutos 'Tanenashi', pero de excelente calidad. El árbol crece verticalmente.

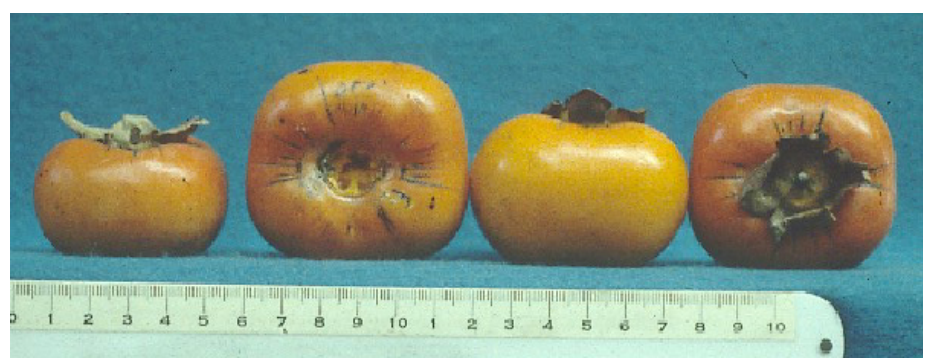

Figura 26. Cultivar 'Great Wall'.

Créditos: Departamento de Ciencias Hortícolas, UF/IFAS

'Tamopan' es un cultivar de fruto grande que tiene una depresión circular alrededor del tercio superior más cercano al tallo (Figura 27). La fruta es jugosa, acuosa y fibrosa, con una cáscara gruesa. Existe más de un variación de este cultivar, algunas de las cuales tienen mejor fruto que el descrito.

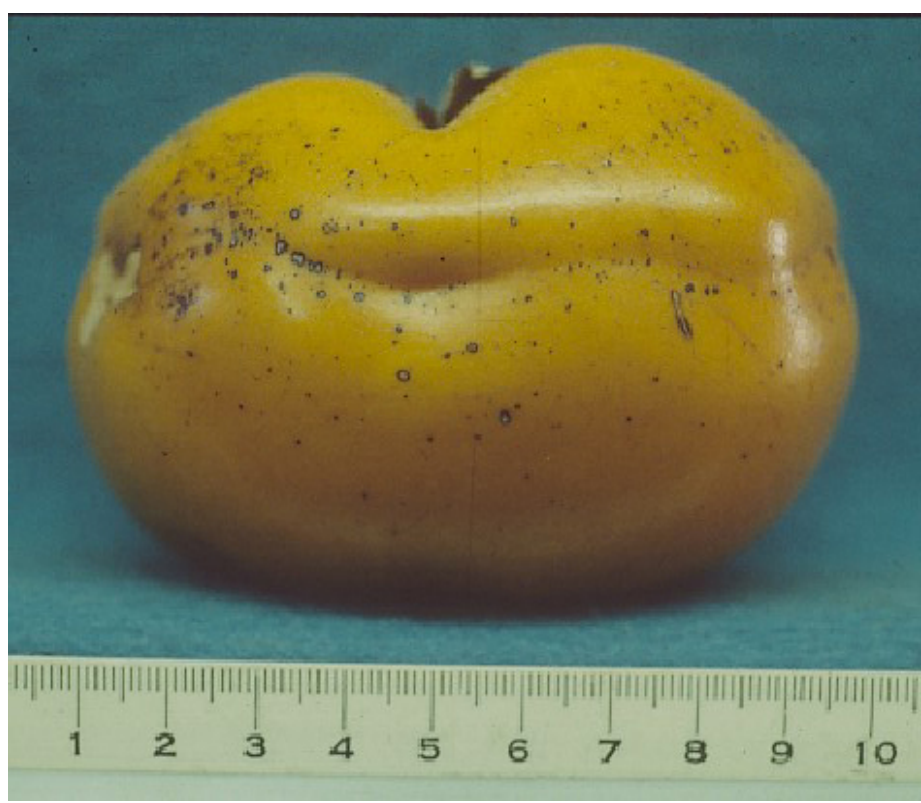

Figura 27. Cultivar 'Tamopan'. Crédito de la fotografía:

Créditos: Departamento de Ciencias Hortícolas, UF/IFAS

'Ormond' es algunas veces llamado el caqui navideño. Sus frutos son largos, cónicos, y a menudo cosechados en enero (Figura 28). El árbol comienza a crecer a principios de la primavera, lo que aumenta las probabilidades de lesiones por heladas. El fruto es jugoso, con semillas grandes.

'Gailey' es el cultivar polinizador estándar y produce frutos de tamaño pequeño a mediano. El agrietamiento de anillos concéntricos en el fruto es común en este cultivar, y es de polinización variante. La pulpa en este cultivar es oscura, incluso si la cantidad de semillas producidas es pequeña. 


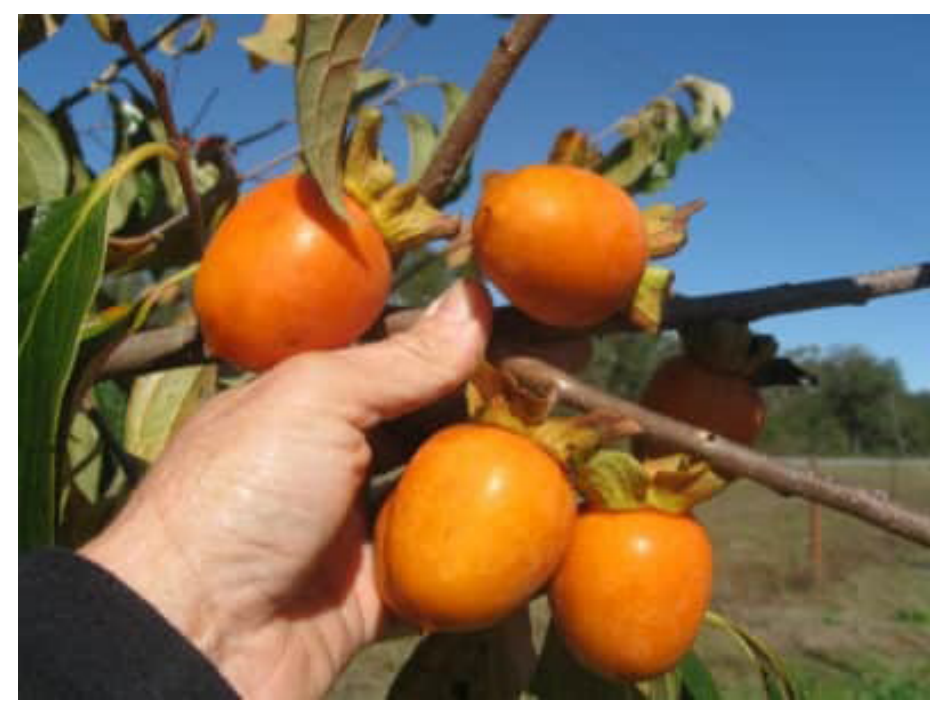

Figura 28. Cultivar 'Ormond'.

Créditos: Just Fruits and Exotics

\section{Cultivares Astringentes Recomendados}

Los cultivares con buen rendimiento se pueden seleccionar para abarcar una temporada de maduración desde mediados de agosto hasta finales de diciembre. Estos cultivares son: 'Nishumura Wase,' 'Saijo,' 'Tanenashi', 'Yamato Hyakume', 'Sheng' y 'Ormond'. 'Nishumura Wase' y 'Ormond' son los cultivares tempranos y tardíos. 'Saijo,' 'Yamato Hyacume' y 'Sheng' producen frutos de pulpa clara y gelatinosa con altos contenidos de azúcar. 'Tanenashi' es el cultivar más ampliamente establecido y generalmente tiene una producción consistente de frutos grandes de calidad media.

\section{Referencias}

Crandall, B. S., and W. L. Baker. 1940. "The Wilt Disease of American Persimmon Caused by Cephalosporium diospyri." Phytopathology 40:307-325.

Edible Landscaping. https://ediblelandscaping.com/ (Source for some pictures).

Hodgson, R. W. 1939. "Floral Situation, Sex Condition, and Parthenocarpy in the Oriental Persimmon." Journal of the American Horticultural Society. 37:250-252.

Itoo, S. 1986. "Persimmon." In Handbook of Fruit Set and Development. 355-370. Boca Raton: CRC Press.

Kitagawa, H., and P. Glucina. 1984. Persimmon Culture in New Zealand. Wellington, New Zealand: Science Information Publishing Center, DSIR.

Knapp, J. 1982. How to Build Orchard and Vineyard Trellises. Pittsburgh: Wire Products, U.S. Steel.
Marzolo, G. 2016. “Persimmon.” Agricultural Marketing Resource Center. https://www.agmrc.org/ commodities-products/fruits/persimmon

Mead, F. W. 1966. "Persimmon psylla." Entomology Circular No. 50. Florida Department of Agriculture, Division of Plant Industry.

Miller, E. P. 1990. "Performance of Non-astringent Persimmons (Diospryos kaki L.) in Florida." Proceedings of the... Annual Meeting of the Florida State Horticulture Society.

Morton, J. F., and C. F. Dowling. 1987. Fruits of warm climates. Vol. 20534. Miami: JF Morton.

Sharpe, R. H. 1966. "Persimmon Variety and Rootstock Observations.” Proc. of Fla. State Hort. Soc. 79:374-379.

Taylor, W. A. 1913. "Promising New Fruits." Yearbook of the United States Department of Agriculture (1902-1913).

US Department of Agriculture. 1960. Index of Plant Diseases in the United States. Agriculture Handbook No. 165. Washington, DC: US Govt. Printing Office.

USDA National Agricultural Statistics Service. 2017. “2017 Census of Agriculture, State and US Data." 
Tabla 1. Desempeño de algunos cultivares ornamentales no astringentes de caqui Diospyros kaki en el UF/FAS NFREC-Monticello durante 1996 (Peter Andersen).

\begin{tabular}{|c|c|c|c|c|c|c|}
\hline Variedad & Rendimientoz (\%) & Supervivencia (\%) & $\begin{array}{l}\text { Índice de } \\
\text { crecimientoy }(\mathrm{m})\end{array}$ & Vigor $^{x}$ & $\begin{array}{c}\text { Resistencia } \\
\text { a daño en la } \\
\text { maderaw }^{w}\end{array}$ & $\begin{array}{l}\text { Peso del } \\
\text { fruto }(g)\end{array}$ \\
\hline ‘Fuyu' & 40.3 & 75 & 3.4 & 5.0 & 5.0 & 204 \\
\hline 'Ichikikei Jiro' & 60.5 & 50 & 3.4 & 4.0 & 6.0 & 182 \\
\hline 'Izu' & 0.0 & 50 & 2.3 & 3.0 & 4.0 & - \\
\hline ‘Jiro’ & 40.7 & 75 & 4.0 & 6.7 & 7.3 & 215 \\
\hline ‘Makawa Jiro’ & 30.5 & 50 & 3.0 & 4.0 & 7.0 & 223 \\
\hline $\begin{array}{l}\text { ‘Matsumoto Wase } \\
\text { Fuyu' }\end{array}$ & 60.0 & 25 & 4.5 & 8.0 & 8.0 & 173 \\
\hline ‘Midia' & - & 0 & - & - & - & - \\
\hline 'Suruga' & 40.5 & 50 & 50 & 4.0 & 4.0 & 177 \\
\hline \multicolumn{7}{|c|}{$\begin{array}{l}\text { " } \text { Rendimiento=Porcentaje de carga de fruto completa } \\
\text { y Índice de crecimiento=(altura de la planta }+ \text { ancho de la planta) }\end{array}$} \\
\hline
\end{tabular}

Tabla 2. Desempeño de algunos cultivares ornamentales astringentes de caqui Diospyros kaki en el UF/IFAS NFREC-Monticello durante 1996 (Peter Andersen).

\begin{tabular}{|c|c|c|c|c|c|c|}
\hline Variedad & Rendimiento ${ }^{z}(\%)$ & Supervivencia (\%) & $\begin{array}{c}\text { Índice de } \\
\text { crecimiento }^{y}(\mathrm{~m})\end{array}$ & Vigor ${ }^{x}$ & $\begin{array}{c}\text { Resistencia } \\
\text { a daño en la } \\
\text { madera }^{w}\end{array}$ & $\begin{array}{l}\text { Peso del } \\
\text { fruto }(g)\end{array}$ \\
\hline 'Eureka' & 40.0 & 100 & 2.6 & 3.3 & 3.5 & 200 \\
\hline 'Giombo' & 20.8 & 100 & 3.9 & 5.3 & 4.8 & 300 \\
\hline 'Sheng' & 30.3 & 75 & 3.0 & 4 & 3.7 & 193 \\
\hline 'Yomato' & 50.7 & 75 & 3.1 & 5 & 7.0 & 221 \\
\hline
\end{tabular}

${ }^{\mathrm{z}}$ Rendimiento=Porcentaje de carga de fruto completa

$y$ Índice de crecimiento $=$ (altura de la planta + ancho de la planta)

×Vigor clasificado en una escala de 1 a 10, con 10 siendo el más alto.

${ }^{\text {w }}$ Resistencia al daño en la madera (Botryosphaeria) del 1 a 10, con 10 siendo el mayor daño. 